\title{
Mexican Guidelines for the Diagnosis and Treatment of Chronic Myeloid Leukaemia
}

\author{
Eduardo Cervera ${ }^{1}$, Federico Godínez ${ }^{2}$, Rosa Sosa ${ }^{3}$, Ramón Rivas ${ }^{4}$, Carlos Best ${ }^{5}$, Juan Hernández ${ }^{6}$, \\ Adrián Morales $^{7}$, Hugo Zurita ${ }^{8}$, Ivette Carrasco ${ }^{9}$, Jorge Cruz ${ }^{10}$, Álvaro Aguayo ${ }^{11}$, José Espinoza ${ }^{1}$, \\ Juan Labardini ${ }^{1}$, Luis Valero ${ }^{1}$, Judith Cruz ${ }^{1}$, Diana Arcos ${ }^{1}$, Diego Limón ${ }^{1}$, Omar López-Navarro ${ }^{1}$, \\ Daniela Gordillo-Bastidas ${ }^{1}$, Myrna Candelaria ${ }^{1}$, Francisco Torres ${ }^{12}$, Juan Kassack ${ }^{13}$, \\ Oscar de Jesús Pérez Ramírez ${ }^{14}$, Jorge Aquino ${ }^{15}$, Guillermo Díaz ${ }^{16}$, Mariela Cardiel ${ }^{17}$, \\ Margarita Rodríguez $^{18}$, Patricia Montoya ${ }^{1}$, Juan Contreras ${ }^{1}$, María Chávez ${ }^{1}$, Sandra Chávez ${ }^{1}$, \\ David Gómez $^{19}$, Olga Cantú ${ }^{19}$, Jorge Duque ${ }^{20}$, Luis Pita ${ }^{21}$, Eduardo Lobato ${ }^{22}$, Julio López ${ }^{23}$, \\ Antonio López ${ }^{24}$, Pedro González ${ }^{25}$, Jorge Cortés ${ }^{26}$
}

\begin{abstract}
${ }^{1}$ Haematology Department, Cancerology National Institute (INCan), Mexico City, Mexico; ${ }^{2}$ Internal Medicine, Haematology, Hospital ISSSTECALI, Tijuana, Mexico; ${ }^{3}$ Haematology Department, General Hospital of Sonora State, Sonora, Mexico; ${ }^{4}$ Haematology Department, Blood Bank and Unit of Aphaeresis, General Hospital of Culiacán, Health Ministry, Culiacán, Mexico; ${ }^{5}$ Haematology, Hospital General de Occidente SSA, Guadalajara, Mexico; ${ }^{6}$ Haematology, Haematology Service, Hospital General Regional SSG, León, Mexico; ${ }^{7}$ Haematology, Oncology Unit, SSEP, Puebla, Mexico; ${ }^{8}$ Haematology Department, Bone Marrow Transplant, and Blood Bank from Hospital Regional de Alta Especialidad "Dr. Juan Graham Casassus", Villahermosa, Mexico; ${ }^{9}$ Haematology, Hospital General de Especialidades, Campeche, Mexico; ${ }^{10}$ Haematology Deparment from Hospital Juárez, Mexico City, Mexico; ${ }^{11}$ Haematology and Oncology Department, National Institute of Medical and Nutrition Sciences "Dr. Salvador Zubirán”, Mexico City, Mexico; ${ }^{12}$ Haematology, Hospital "Aranda de la Parra", León, Mexico; ${ }^{13}$ Haematology, Hospital General de México, Mexico City, Mexico; ${ }^{14}$ Haematology, Head of Haematology Service, School of Medicine, Autonomous University of San Luis Potosí, San Luis Potosí, Mexico; ${ }^{15}$ Haematology, Hospital Regional de Alta Especialidad de Oaxaca, Oaxaca, Mexico; ${ }^{16}$ Leukaemias Clinic at ISSEMyM, Toluca, Mexico; ${ }^{17}$ Haematology Department, Centenario Hospital, Miguel Hidalgo, Health Ministry, Aguascalientes, Mexico; ${ }^{18}$ Haematology, Mérida Clinic, Yucatán, Mexico; ${ }^{19}$ Haematology Department, Hospital Universitario UANL, Monterrey, Mexico; ${ }^{20}$ State Council for AIDS Prevention and Control, Chihuahua, Mexico; ${ }^{21}$ Renaissance Clinic, Morelia, Mexico; ${ }^{22}$ Hospital Betania, Puebla, Mexico; ${ }^{23}$ Los Mochis General Hospital, Sinaloa, Mexico; ${ }^{24}$ Hospital of the Poblano Child, Puebla, Mexico; ${ }^{25}$ Universidad Autónoma de Yucatán, Mérida, Mexico; ${ }^{26}$ Leukemia Department, MD Anderson Cancer Center, Houston, Mexico. Email: eduardocerverahematol@yahoo.com.mx, eduardocer@yahoo.com
\end{abstract}

Received December $29^{\text {th }}, 2012$; revised January $31^{\text {st }}, 2013$; accepted February $8^{\text {th }}, 2013$

Copyright (C) 2013 Eduardo Cervera et al. This is an open access article distributed under the Creative Commons Attribution License, which permits unrestricted use, distribution, and reproduction in any medium, provided the original work is properly cited.

\begin{abstract}
Background: This document includes recommendations and guidelines issued by a group of Mexican researchers and specialists gathered in the First National Colloquium for the Diagnosis and Management of Chronic Myeloid Leukaemia (CML) by initiative of Instituto Nacional de Cancerología and with the support of the Leukaemia Department of the MD Anderson Cancer Center. Mexico lacks of updated information taken from its own reality on the diagnosis and treatment of CML and other haematological disorders; besides, there are no national guidelines. Aim: To publish a consensus document with guidelines for the management of CML adjusted to the national environment and overall characteristics. Method: The participants answered a DELPHI questionnaire about the overall aspects of the disease, aiming to target controversial topics, discuss them in the colloquium, and to agree on the best ones. After those meetings, a final document was drawn up. Results: The group presents recommendations for definition, diagnosis, prognosis, monitoring, and treatment of CML in Mexico. Conclusions: Having consensus guidelines for the clinical management of CML in our country will enable the consensual practice of Mexican specialists regarding the clinical approach to $\mathrm{CML}$, as well as optimize the resources which allow the rational planning of the medical care strategies.
\end{abstract}

Keywords: Chronic Myeloid Leukaemia; Management Guidelines; Diagnosis; Treatment.

\section{Introduction}

Chronic Myeloid Leukaemia (CML) is a clonal and myeloproliferative expansion of the transformed haematopoietic stem cells. Such expansion includes the myeloid stem cells lineage, and others. The CML was the 
first human disease related to a genetic disorder (Philadelphia chromosome, $\mathrm{Ph}$ chromosome and/or $\mathrm{Ph}+$ chromosome [positive]). The most reliable incidence statistics may be the American one, which reports 1 to 2 cases of CML per 100 thousand people every year. This disease stands for $15 \%$ of leukaemias among adults [1]. Mexico lacks of a reliable incidence rate, although such leukaemia is regarded as the most treated one. In Mexico, CML seems to appear earlier-between 37 and 40 years oldthan in Caucasian populations, where it is frequent to find among adults in their 66 years old [2].

The CML classification proposed by the World Health Organization is functional; nevertheless, other classifications are used. Such classifications are based on clinical trials findings with tyrosine kinases inhibitors (TKI), particularly with imatinib mesylate which has proven to be effective in the treatment of a sound proportion of patients with CML. The classification based on experience with imatinib is much more operationally objective and supports proper updated expectations for every stage of the disease [3]. Recently, European Leukemia Net (ELN) used this classification system to group the disease within the context of its guidelines for the treatment of the CML [4].

The international recommendations about CML may be applied to Mexico, but there are characteristics which demand local guidelines. At diagnosis, it is recommended to show the presence of $\mathrm{Ph}+$ and/or the $\mathrm{BCR} /$ ABL transcript. The methods which may be used are karyotype, FISH (Fluorescence in situ hibridization), and qRT-QRT-PCR (quantitative real time polymerase chain reaction). Nevertheless, there is disagreement on performing them when they are used to diagnose and in the follow-up. It is recommended to classify the patients with a Sokal score.

Imatinib is the first line treatment in patients in chronic phase. Dasatinib and nilotinib should also be considered as effective first line treatment. Choosing TKI as the front-line treatment for CML in chronic phase must be a decision taken according to age, risk disease, comorbidity, security profile, cost, and availability [5].

When treatment with imatinib fails or the patient does not tolerate it, second line treatment includes nilotinib or dasatinib. When the outcome is suboptimal or nilotinib and dasatinib are not available, alternative doses of imatinib are $600 \mathrm{mg}$ or $800 \mathrm{mg}$. The stem cell transplantation (SCT) is a second or third line treatment when there is resistance to second generation TKIs. The accelerated or blastic phases must be treated with TKI plus chemotherapy and SCT.

There are definitions of haematological, cytogenetic, and molecular outcomes which may be accomplished in a pre-established period of time to reach the best outcome to treatment. It is not recommended to frequently determine mutations or serum levels of TKI $[6,7]$.

\section{Method}

The most important bibliography was analyzed; including the latest versions (when this document was being drawing up) of the most followed recommendations around the world: the European Leukemia Net (ELN) [1] and the National Comprehensive Cancer Network (NCCN) [2].

A group of experts in diagnosis and treatment of CML was chosen to represent a certain geographical area, among entire Mexico. They were distributed in 5 teams as follows:

1) Epidemiology and natural history of CML;

2) Diagnosis and follow-up;

3) Management in first and second lines;

4) Transplantation;

5) Management in blastic and accelerated phases.

A coordinator was assigned for every topic. The coordinators' duties consisted of giving bibliography to their groups, moderate team work during the session; monitor members meet the programme deadlines, and name a secretary who will properly draw up the conclusions of the team discussion during the colloquium. Delphi questionnaires were developed for groups 2,3 , and 5 with the purpose of reaching a consensus on controversial issues which will be discussed by the group. The clinical trials, laboratories and reference institutions were analysed. For the main recommendations proposed, a GRADE classification is provided to identify the level and the scope of the sentences.

\section{Epidemiology and Natural History of CML}

The American reported incidence of CML is 1 to 2 cases/ $100,000 /$ year, which stands for $15 \%$ of the leukaemias in adults [7]. Mexico lacks of information about this disease; nevertheless, chronic leukaemia is the most frequent diagnosis in clinical practice. Most of the cases (86\%) are diagnosed in chronic phase, $7 \%$ in accelerated phase, and $7 \%$ in the blastic one. Likewise, median age at diagnosis is different from the age in Caucasian countries - median age is 66 years old (SEER) [8] - mainly between 37 and 40 years old [9-11]. Therefore, this indicates the disease affects the most economically productive population. Even though prevalence of CML has not been defined altogether, in 2008 Corn informed that in the North of France the prevalence increased $4.1 \%$ annually from 1998 to 2002; and 9.3\% from 2003 to 2007. This rise responds to the administration of imatinib therapy, which in turn had an effect on patients' survival. This is somehow similar with moderate therapies based in TKI in Mexico and the rest of the world [12]. The most common findings are anaemia, haemorrhage, fever, splenomegaly, 
and hepatomegaly. Only $20 \%$ of the patients is asymptomatic; thus, it seems that in Mexico there are more patients with high Sokal risk, compared with the information obtained in USA and Europe [9]. The disease is characterized by a natural triphasic or biphasic course [10]. Before the management with TKIs, survival in chronic phase was estimated in 3 to 5 years; the accelerated one in less than a year; and the blastic one in 3 to 6 months [13].

\subsection{Phases and Definitions}

The existing criteria for distinguishing every phase of the disease are rather different and are divided into: WHO classification system and the classification based on clinical trials with TKIs. The difference is so critical that it is likely to reclassify the cases using one or the other system [14]. In this document, we recommend the system based in clinical trials with imatinib because it is much more objective, easy to find, and reflects the pathological clinical status of CML; besides, it is supported by prospective clinical trials with the current therapy which allow the establishment of expectations for every phase.

Recently, ELN applied this classification system in order to group the disease according to the recommendations for the management of CML (Table 1 [15]) [16].

\subsection{Physiopathology (Molecular Biology)}

On the whole, the diagnosis of CML is based on the identification of the Philadelphia chromosome. This abnormality was described in 1960 as a short chromosome 22 ; then, in 1973 as a translocation $t(9 ; 22)$ [17], which is present in $95 \%$ of the patients [18].

The increase in expression of $\mathrm{BCR} / \mathrm{ABL} 1$ is related to the disease progress to an accelerated phase. Although this is not well-understood, it may derive in mechanisms which favour the expansion of differentiated leukaemia cells. The over expression and /or activation of genes and metabolic pathways as SFK, HCK, LYN y FYN have

Table 1. Clinical phases of Chronic Myeloid Leukaemia [Adapted from 15].

\begin{tabular}{|c|c|c|}
\hline Accelerated phase & Blastic phase & Chronic phase \\
\hline $\begin{array}{l}\text { Blasts in peripheral blood or } \\
\text { bone marrow } 15 \text { to } 29 \%\end{array}$ & $\begin{array}{l}\text { Blasts in peripheral } \\
\text { blood or bone } \\
\text { marrow } \geq 30 \text { or }\end{array}$ & $\begin{array}{l}\text { The chronic } \\
\text { phase definition } \\
\text { implies that }\end{array}$ \\
\hline $\begin{array}{l}\text { Summation of blasts plus } \\
\text { promyelocytes in peripheral } \\
\text { blood or bone marrow }>30 \% \text {, } \\
\text { but with blasts cells }<30 \%\end{array}$ & $\begin{array}{l}\text { extramedullary } \\
\text { infiltrates of } \\
\text { blasts cells }\end{array}$ & $\begin{array}{l}\text { none of the } \\
\text { criteria for } \\
\text { accelerated } \\
\text { and blastic } \\
\text { phases are }\end{array}$ \\
\hline $\begin{array}{l}\text { Basophiles in peripheral blood } \\
\geq 20 \%\end{array}$ & & met. \\
\hline $\begin{array}{l}\text { Persistent thrombocytopenia } \\
\text { (platelets }<100,000) \\
\text { not related with treatment }\end{array}$ & & \\
\hline
\end{tabular}

been associated with progression of CML and resistance to imatinib. The consequence of BCR/ABL1 is a DNA chronic oxidative damage, cell cycle arrest at phases $\mathrm{S}$ and G2/M, which enables mutagenesis. About $80 \%$ of the patients with CML develops cytogenetic aberrations (non-randomized in positive $\mathrm{Ph}$ ), known as clonal evolution, which imply a genetic instability and characterised the transition to advance phases. One of the most common mutations, related to progression on CML, includes the p53 tumour-suppressor gene and is present in $25 \%$ $30 \%$ of the patients with myeloid blastic phase [19-31].

\subsection{Molecular Biology}

CML is characterised by the presence of the Philadelphia chromosome, which is a shortening of the chromosome 22 and product of a translocation $\mathrm{t}(9 ; 22)$ (q34; q11). Such translocation adds a region 3 ' of the $\mathrm{ABL}$ gene in the $9 \mathrm{q} 34$ chromosome to the region $5^{\prime}$ of the BCR gene in the q11 region in the chromosome 22 . Consequently, a hybrid gene $\mathrm{BCR} / \mathrm{ABL} 1$ is created and transcribed in a chimeric mRNA (BCR/ABL1) which encodes a tyrosine kinase-like protein.

The breakpoints of the ABL gene are located at exons a2 to 11 , while the ones in the BCR are in exons 12 and 16 (exon b1 to exon b5). Depending on the breakpoints involved, there will be 4 different variables: a1a2, b2a2, b3a2, and e19a2, closely related to CML (Figure 1 [32]) [16].

ABL gene has a binding domain to DNA and a Y-Cinase domain, while BCR gene contains an autophosphorylation domain. When the fusion BCR/ABL1 takes place, the result is a tyrosine kinase-like protein type $\mathrm{C}$ with autophosphorylation capacity, which enables survival and cell proliferation signals (Figure 2[33]) [16].

As a consequence of a high tyrosine kinase activity, protein BCR/ABL1 may phosphorylate several substrates which will activate different signaling pathways and affect the cell growth and differentiation. These substrates include CRKL, p62Dok, paxiline, CBL, and RIN which activate pathways involving RAS, RAF, P13K, AKT,

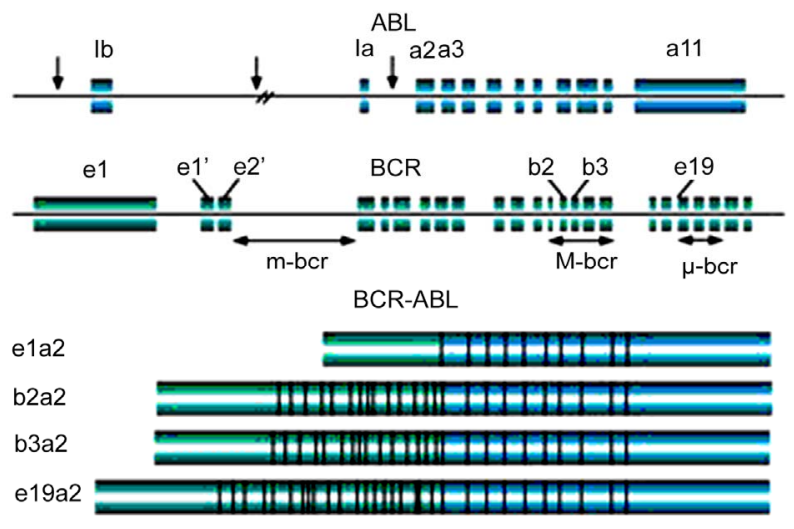

Figure 1. Breakpoints of the ABL gene [Adapted from 32]. 


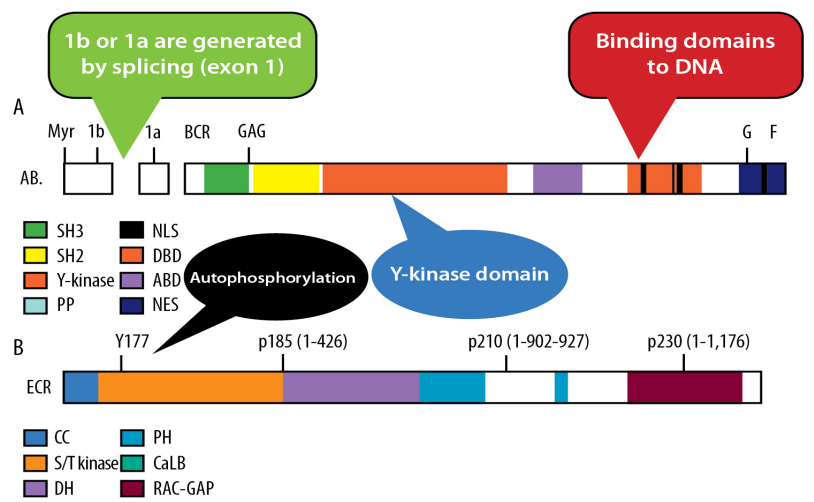

Figure 2. Survival and cellular proliferation signalling pathways promotion [Adapted from 33].

JUN kinase, MYC, and STAT. Such pathways have not been well-defined; nevertheless, it is known that $\mathrm{BCR} /$ ABL1 activates the same signaling pathways, which are triggered by cytosines and control the growth and differentiation of normal hematopoietic cells.

Unlike other fusion oncogenes, which are associated to human leukaemia (MLL-ELN or MOZ-TIF2), BCR/ABL1 may transform hematopoietic stem cells (HSC), but it is not enough to transform the compromised myeloid progenitors when there is a lack of self-renewal capacity.

In CML, the leukaemic stem cells (CD34+, CD38-Lin-) express high levels of transcripts BCR/ABL1. During the transition from chronic phase to the blastic one, leukaemic stem cells acquire genetic and/or epigenetic abnormalities which lengthen survival, resistance to a programmed death, and a more extended replication.

These data suggest that the blastic phase may be the product of genetic alterations inside the progenitor hematopoietic cell lineage, which gives self-renewal properties [34-36].

\section{CML Diagnosis and Prognosis}

\subsection{Disease Progression}

Acquiring additional chromosomal changes is related to the accelerated and blastic phases of the disease. They include monosomy of chromosome 7 , translocation $(3 ; 21)$, extra copies to the translocation $(9 ; 22)$, trisomy of chromosome $\mathrm{Y}$, and abnormalities of chromosome 17, among others.

Recent clinical trials have suggested a prognostic importance at the loss of the chromosomal region which derives from the long arm of chromosome 9q. Patients with losses at breakpoints in this chromosome have a more aggressive disease, with a fast development to a blastic crisis; nevertheless, imaninib treatment reduces the prognostic importance of this abnormality [16]. Abnormalities in chromosome 17 are the result of mutations at $\mathrm{p} 53$, which have been found only in the blastic mye- loid crisis.

The progressive fibrosis of bone marrow is associated with transformation and may produce progressive bone marrow failure. It has been informed that bone marrow fibrosis, at diagnosis and confirmed by means of reticulin staining, is severe in $40 \%$ of the cases and is usually associated with a poor prognosis [37]. Nevertheless, in the imatinib era, the importance of fibrosis - as prognosishas decreased.

As a rule, the most common cause of death is the transformation to the accelerated or blastic phase. In the accelerated phase, citopenias may develop and, in turn, cause much more morbidity, but the main cause of death is the transformation to the blastic phase: $50 \%$ of the patients present a myeloid blastic crisis, $25 \%$ have a lymphoid phenotype, and $25 \%$ have a not well-differentiated phenotype.

The CML diagnosis should be establish by means of recognition of $P h$ positive or the rearrangement of $B C R /$ $A B L$.

It is recommended that the presence of $P h$ positive and/or BCR/ABL transcript must be identified in every patient with clinical suspicion of CML.

Category of evidence: A Recommendation grade: 1 .

\subsection{Methods}

The methods used to diagnose are karyotype, FISH, and QRT-PCR. Recommendations to use these methods may differ according to the moment they are performed: at diagnosis or in the follow-up.

Karyotype. The main advantage of karyotype is that it enables the identification of cytogenetic alterations, besides the $\mathrm{Ph}$ positive, which influence prognosis. It is recommended to:

- Go to certified laboratories with experience in cytogenetics protocols for oncological diseases.

- Preferably, this test should be performed in bone marrow with $10 \%$ of sodium heparin or lithium heparin, and keep the sample at room temperature.

- The laboratory must receive the sample optimally in the first 24 hours after being drawn, with a minimum volume of $2 \mathrm{ml}$.

- The test must include, at least, 20 analyzable metaphases. When positivity is confirmed, two outstanding cytogeneticists must review it independently. Images must be printed or kept in an electronic format for future reference.

- Some treatments, like interferon, may alter the cell proliferation and decrease the number of analyzable metaphases; thus, it is suggested to perform the test before administering a cytoreductive treatment or wait for a "washing" period, at least one week before the test is carried out again. This does not 
happen with TKI. At the moment of performing the test, the patient must indicate if she or he receives a drug which may alter the results. The report must be drawn up according to the recommendations of the international system of human cytogenetic nomenclature 2009 (ISCN 2009) [1].

- In patients with secondary myelofibrosis, it is recommended to collect the sample and use FISH test to identify the fusion gene BCR/ABL.

FISH. It is the only test which identifies loss of derivative 9; however, it does not detect associated cytogenetic alterations. It may give false positives between $1 \%$ and $10 \%$, depending on the used probe. It is performed in interphase cells (FISH-I); thus, it is not necessary that the cells be in metaphase.

- It is recommended at diagnosis when the karyotype is not an option because of an absence or poor quality of the test.

- It may be successfully performed in peripheral blood, even if the patient is receiving an antileukaemic treatment.

- It is recommended to use dual probes for BCR and $\mathrm{ABL}$, as well as to analyse a minimum of $200 \mathrm{nu}-$ clei.

$Q R T-P C R$. It detects transcripts of mRNA in $\mathrm{BCR} /$ ABL.

- It cannot replace karyotype or FISH at diagnosis.

- Its availability is not enough in our country. Sometimes, it may give false negatives when there are variants of the non-detectable transcript BCR/ABL.

- So far, it has not been considered essential to perform it at diagnosis.

- While FISH positive confirms disease, it has not been accepted as a test to confirm cytogenetic response, which is performed by means of karyotype.

\subsection{Complementary Tests to the Diagnosis}

The complementary tests are useful to determine the CML stages and specify the prognosis.

In all the patients it is recommended to perform:

- Complete Blood Count with peripheral blood smear because knowing the number of basophiles, eosinophiles and blasts is useful. Likewise, it is recommended to perform a complete biochemical profile as a record to evaluate the toxicity criteria with the used treatment.

- Measure of spleen. The prognostic scores use the clinical measure of the spleen, taking into account its costal margin.

- $\quad$ The bone marrow aspirate is necessary to group CML and to perform karyotype. Above all, the number of blasts and basophiles are taken into account.

Category of evidence: B. Recommendation grade: 1 .

\subsection{Other Test at Diagnosis}

- Bone biopsy. Although there is information about its usefulness, most of it comes from the previous time to the administration of TKIs treatment. Nowadays, its value has decreased mainly because fibrosis may be reversed with imatinib [37]. It may be considered a convenient test, but not indispensable.

Category of evidence: $C$ Recommendation grade: 2 .

Mutations at the region $B C R / A B L$. There is no current evidence of its usage at diagnosis. Besides, as it is not available in our country and it is very expensive, it is not regarded as an initial test.

\subsection{Recommendations to Establish Diagnosis}

At diagnosis, there is no practice prognostic score proposed during treatment with TKIs. Nevertheless, the scores previously established, like Hasford and Sokal, have demonstrated an impact on treatment response with interferon and even with imatinib in chronic phase.

The results of the IRIS trial confirmed it at the 12month follow-up with complete cytogenetic response (CCR) of $78 \%, 68 \%$, and $51 \%$ for the groups of low, intermediate, and high risk of Sokal, as well as major molecular remissions (MMR) among the CCR of $66 \%$, $45 \%$, and $38 \%$, respectively [38]. The influence of the prognostic group of Sokal is also observed in the overall survival (OS), progression-free survival (PFS) to accelerated or blastic phases, and event-free survival (EFS) within 6 years with $94 \%, 97 \%$, and $91 \%$ for the low risk group; $87 \%, 92 \%$, and $81 \%$ for the intermediate risk; and $76 \%, 83 \%$, and $64 \%$ for the poor prognostic group, respectively [39]. Nevertheless, once the CCR is accomplished, the Sokal score influence disappears (PFS of $99 \%, 95 \%$, and $95 \%(\mathrm{p}=0.2))[40]$.

The poor prognostic group is the one which has more influence in response and survival, since the low and intermediate groups overlap, above all when imatinib is administered. Since most of the studies have used Sokal score, it is recommended if no other score shows clinical utility.

The time between diagnosis and treatment with imatinib or transplantation may influence prognosis, as it is shown in some trials [41]. Thus, it is recommended to begin with specific treatment as soon as diagnosis is established. The presence of other additional chromosomal alterations to the Philadelphia chromosome predicts a briefer OS and a PFS [42].

Using Sokal score as a predictive system would allow a better uniformity when analyzing the results of different regions of our country. If this score is wanted to be used, there is information on the web or in electronic devices which can automatically work out the risk. 
It is recommended to use the prognostic Sokal score at diagnosis in every patient with CML in chronic phase.

Category of evidence: B Recommendation grade: 1 .

Recently, the European group has validated a predictive response score to TKI (EUTOS Score). Although it is simple, practical, and reproducible it has not been approved for our population. Thus, it is suggested to evaluate it in our patients.

\subsection{Follow-Up}

Once established the CML diagnosis, the detailed followup of the evolution of the patient is crucial to choose the proper treatment. The careful monitoring response and toxicity is the base for a better medical practice.

\subsection{Types of Response in CML}

There are three types of response in CML: haematological, cytogenetic, and molecular. The first therapeutic objective of CML is acquisition, as soon as possible, of cytogenetic response which in patients in chronic phase is usually preceded of complete haematological response.

Category of evidence: A Recommendation grade: 1.

However, the molecular response has acquired a noteworthy magnitude. It takes place after CCR, and its importance lies on the fact that no patient with complete molecular response progress to accelerated and blastic phases.

\subsection{Haematological Response}

The haematological tests and blood counts are the earliest and most common ways of monitoring. They are the key to detect severe (but fortunately rare) case of primary resistance to treatment (when imatinib is used as firstline therapy). This follow-up continues during the all the treatment for monitoring toxicity, and it is not the first relapse indicator (in reverse to acquisition of relapse, the haematological recurrence is usually preceded by cytogenetic relapse, which in turn is preceded by relapse or molecular progression). Needless to say, the importance of careful morphological review of peripheral blood is determinant from diagnosis, as well as the value of review of bone marrow with specific identification of basophiles, eosinophiles, and myeloid cells in different stages.

The loss of complete haematological response (CHR) in patients who receive imatinib and did not have molecular cytogenetic response (MCR) or complete cytogenetic response (CCR) is an ominous sign and must be treated in an effective way, usually with second generation TKI.

Category of evidence: A Recommendation grade: 2.

\subsection{Cytogenetic Response}

The cytogenetic response (CR) is characterized by gradual decrease of positive $\mathrm{Ph}$ metaphases number, worked out by means of bone marrow aspiration and cytogenetic evaluation. Chromosomal monitoring is the most widely used test for the response follow-up in patients with CML. It is becoming the golden standard because of its availability, consistency, and meaningful difference in survival, among the patients with CR vs. the patients who do not present it.

\subsection{Types of Cytogenetic Response}

As the treatment continues, there must be a gradual decrease in the number of metaphases positive to Philadelphia chromosome. Likewise, time to assess response has been agreed in order to establish specific features which relate positive $\mathrm{Ph}$ metaphases/time by means of extrapolating the number of positive $\mathrm{Ph}$ cells as leukaemic residual mass. Thus, based on $100 \%$ of original $\mathrm{Ph}$ positive cells at diagnosis, some defining criteria have been proposed to identify the different types of cytogenetic response.

Category of evidence: A Recommendation grade: 1 .

The capacity of conventional cytogenetic of detecting the clonal cytogenetic evolution (CCE) is quite important because it may be predictive when it is obtained in presence of the Philadelphia clone, and when conspicuously appears in the evolution of advanced stages of the disease (accelerated phase by CCE and/or blastic phase).

On the contrary, the presence of additional cytogenetic alterations (ACA) - in the context of a karyotype without $\mathrm{Ph}$ - may seem not to imply a poor prognosis; and the only recommendation is to monitor their evolution by karyotype. The most common alteration is trisomy 8 and the one with the worst prognosis is the loss of -7 chromosome, with a potential myelodysplastic syndrome [43].

\subsection{Frequency of Cytogenetic Evaluation}

Cytogenetic assessment is recommended every six months, after front-line treatment with imatinib. Recently, it has been suggested that the first assessment be performed at three months, particularly when administering effective drugs like second generation TKIs [1]. In the case of imatinib, it is important to consider that, although new ELN recommendations suggest performing karyotype in bone marrow at three months, this test is convenient, but not indispensable because of its poor availability in Mexico and because if there is no $\mathrm{CR}$ ( $\mathrm{Ph}$ positive $>95 \%$ ) it would be interpreted as a suboptimal response and not as a failure. Then, it would not be necessary to change treatment, just maintaining imatinib in the same or higher doses. Once CCR is reached, it is recommended to 
monitor every 12 months or when suspecting failure or cytopenias (ELN).

Category of evidence: B Recommendation grade: 2 .

Cytogenetic relapse. In any moment, a cytogenetic response may be lost. This indicates treatment failure, which leads to modify it. In these cases is critical to regard the compliance to treatment. If this is the correct one, an effective treatment must be administered: increasing imatinib dose, or ideally administering nilotinib or dasatinib. Cytogenetic relapse must be prevented to progress to haematological relapse, because the prognosis worsens.

Besides a clinical trial, the best recommendation in this moment is limiting the chromosomal surveillance in patients who have CCR and present increase in transcripts $\mathrm{BCR} / \mathrm{ABL} 1$ by quantitative real time polymerase chain reaction (qRT-QRT-PCR) or with persistent or recently acquired cytopenias.

Category of evidence: C Recommendation grade: 2 .

FISH. The CR may be assessed by more sensitive tests like the molecular cytogenetic FISH, both in peripheral blood and in bone marrow. It is an important diagnostic tool used mainly for diagnosing CML. Several trials have confirmed a good correlation between cytogenetics of the bone marrow and FISH, particularly in retrospective trials as well as in correlation trials.

Nevertheless, ELN does not recommend this technique because in the prospective response trials with TKIs, the cytogenetic assessment is performed with karyotype. Therefore, FISH is recommended as a complimentary technique to the conventional cytogenetics; thus, every laboratory must establish the cut-off point of the used probe for the detection of the fusion gene BCR/ABL. After that, FISH is regularly recommended unless:

- It is not possible to obtain bone marrow aspirations or metaphase cells enough to karyotype;

- There is no good-quality conventional cytogenetics which assures a satisfactory outcome, (for instance, lack of proper metaphases for the analysis);

- There is no access to good qRT-QRT-PCR;

- Possibility of false positives and lack of information about other chromosome alterations.

Category of evidence: C Recommendation grade: 2 .

\subsection{Molecular Response}

Once the CCR is obtained, the scope of the response may be measured by taking into the account the number of chimeric BCR/ABL mRNA transcripts. This implies the performance of molecular techniques like qRT-QRTPCR. The molecular response is determined by the gradual decrease in the amount of transcripts. The major molecular response (MMR) indicates decrease in at least three algorithms (or more) of chimeric RNA related to the basal quantification (but with detectable transcripts).
The complete molecular response (CMR) takes place when, in spite of the current qRT-QRT-PCR, there is no detection of chimeric RNA transcripts.

The qRT-QRT-PCR technique may be performed in a qualitative way, and its results are regarded as positive or negative. When this technique is used with nested QRT-PCR is very useful. The qRT-QRT-PCR advantage is that it reveals the real percentage of $\mathrm{BCR} / \mathrm{ABL}$ transcripts; thus, it is the most reliable result related to residual leukaemic mass. Another advantage is that qRTQRT-PCR has a remarkable correlation between results obtained from peripheral blood and from bone marrow, which prevents bone marrow punctures and aspirations. However, they are not equivalent; then it is always recommended to use peripheral blood.

The qRT-QRT-PCR is the most used technique around the world to detect $\mathrm{BCR} / \mathrm{ABL}$ transcripts in peripheral blood or in bone marrow. It can detect a CML cell among 100,000 normal cells.

Most of the patients treated with imatinib acquire CCR, but only a small percentage acquires MCR. As a rule, the BRC/ABL transcripts diminish slowly after CCR. The patients who accomplish molecular, major or complete response have a better diagnosis. Consequently, qRTQRT-PCR has demonstrated its usefulness for monitoring molecular response, after CCR. Due to the potential different variables which may participate in the qRTQRT-PCR, a world effort has been made to determine an international conversion to homologate the results from all the participating health centres as well as uniform the criteria for molecular response.

Category of evidence: A. Recommendation grade: 1 .

Countless efforts are made to improve the standardization of qRT-QRT-PCR. Once some certain quality requirements are met, the individual laboratories will be able to use their own technology, but they must apply a specific conversion tool with the purpose of expressing their data in an "international score". A value of $100 \%$ in such score would be close to the median leukaemic load in $\mathrm{BCR} / \mathrm{ABL}$ transcripts at diagnosis (obtained from the basal data of the IRIS trial). Then, $0.1 \%$ corresponds to reduction of three algorithms and defines MMR. Nowadays, it is recommended to use this international score and to count on world standardized reference laboratories, because when this technique is not approved, it may give wrong results which disorient the physician, rather than help him/her.

With respect to cytogenetic and molecular response, several trials have demonstrated that MMR is associated with long-term remission rates and an excellent freeprogression survival with imatinib. Likewise, the early molecular response is a favourable prognostic factor to prevent the disease progression.

In consequence, MMR is the ideal goal, since it places 
the patient in a "high-security" response which prevents the disease progression.

Category of evidence: A. Recommendation grade: 1 .

Molecular relapse. The continuous increase in the number of transcripts may suggest resistance or treatment failure. However, when there is no resistance data, any rise in the number of transcripts must be confirmed with a second sample, particularly in the case of low levels of $\mathrm{BCR} / \mathrm{ABL}$, where the imprecision in the quantification of $\mathrm{BCR} / \mathrm{ABL} 1$ is evident.

Category of evidence: C Recommendation grade: 2 .

It is strongly advised that, when haematological, chromosomal or molecular results be bordering or conflicting, a second analysis must be performed.

\subsection{Optimal Response to First-Line Imatinib Treatment}

The optimal, suboptimal, and treatment failure to imatinib have already been defined in previous lines, as well as the second generation TKIs. These protocols have been recommended in several consensus and guidelines, manly in the NCCN guidelines and in the ELN consensus $[1,44]$.

\subsection{Mutation Determination in Tyrosine Kinase Domain}

The typical mutations (change of an amino acid for another one) in the final sequence of the resulting oncoprotein may be a common finding. Nevertheless, many of those changes are not crucial in the clinical context. At present, there is no justification for the routine determination of mutations in the kinase domain, nor at diagnosis (basal) or periodically during the follow-up, particularly in patients with a good response. In fact, the finding of transient mutations in patients with stable CCR has been reported and it does not alter the prognosis or disease progression which suggests that detecting a mutation is not essential for the therapeutic failure, when there is no increase in leukaemic mass.

Taking all this into account, besides the fact that Mexico does not have a reference health centre which performs it, it is not recommended to detect mutations unless treatment with TKIs fails.

Category of evidence: C Recommendation grade: 2.

\subsection{Imatinib Plasma Levels Determination}

A recent trial showed that patients with high levels of imatinib in plasma had a correlation with high rates of CCR and MMR. In a subanalysis of the IRIS trial, patients with low concentrations of imatinib on day 29 were not so prone to acquire CCR and MMR. This suggests that the measure of the plasma concentrations may identify patients, where the adjustment of doses was useful.
However, there is neither international consensus nor enough data in the literature to approve monitoring plasma levels as part of routine follow-up [45].

It is not recommendable to routinely measure plasma levels.

Only certain chosen cases may benefit from this measure, such as patients with resistance, with severe and unusual adverse effects, and the ones with poor compliance or pharmacological interference.

Category of evidence: C Recommendation grade: 2 .

\subsection{Haematological, Cytogenetic, and Molecular Response Criteria}

It is recommended to follow the NCCN guidelines for the clinical oncologic practice in Chronic Myeloid Leukaemia V.2.2011.

\section{First and Second Lines Treatment}

\subsection{Chronic Phase Treatment}

First-line treatment with imatinib. IRIS trial results, at 7 years, show a sound superiority of imatinib over the combination of IFN- $\alpha /$ cytarabine [46]. None of the patients who reached MMR at 12 months has progressed to advanced phases. At 7 years, $86 \%$ of the patients have reached MMR. The progression rate at 4 and 7 years has been $0.9 \%, 0.5 \%, 0 \%$, and $0 \%$, respectively [46].

These results are expressed in terms of survival and a significant reduction of progression, with less adverse effects than IFN- $\alpha /$ cytarabine combination: OS $85 \%$; PFS 92\%, and FDS $81 \%$.

The first-line treatment recommended for patients with CML in chronic phase has been imatinib mesylate (400 $\mathrm{mg} /$ day) in just one dose. Its low cost, effectiveness in a considerable number of patients and follow-up time with imatinib, compared with second generation TKIs, proves it is the best choice as first-line treatment. Nevertheless, every patient must receive a treatment according to her/ his clinical condition.

Category of evidence: A. Recommendation grade: 1 .

Nevertheless, in 2010, the FDA and the European regulatory agencies authorized nilotinib and dasatinib as the first-line treatment, and they are also approved as first-line treatment since 2011 in Mexico.

\subsection{Response to Imatinib}

The response to imatinib is defined according to European Leukaemia Net (ELN) recommendations [1].

\subsection{Optimal Response}

The optimal response indicates that the treatment is being successful and there is no need of modification. 


\subsection{Suboptimal Response}

The suboptimal response is, by definition, a transient response. It may progress to optimal response or to failure $[47,48]$.

Dose adjustment is recommended; daily dose of 400 $\mathrm{mg}$ of imatinib may be adjusted to 600 or $800 \mathrm{mg}$ when a patient meets with suboptimal response. Doses higher than $800 \mathrm{mg}$ are not recommended.

Category of evidence: B. Recommendation grade: 2 .

A therapeutic option may be second generation TKIs like dasatinib or nilotinib (see second generation inhibittors section).

Nevertheless, there are no prospective data about the long-term benefit of the dose adjustment of imatinib or the second generation inhibitors in case of suboptimal response.

Category of evidence: C Recommendation grade: 3 .

Imatinib must be stopped in case of failure (according to ELN criteria) [1] or intolerance with toxicity (grades 3 to 4) and to change to second generation treatment.

\subsection{Failure}

There may be primary (response with imatinib was never achieved) or secondary (after a kind of response with imatinib) resistance. The secondary resistance is much more frequent. The most common resistance mechanism is the development of mutations in the BCR/ABL1 kinase domain. Some others are: clonal cytogenetic evolution, over-expression or amplification of the gene, and decrease of bioavailability or in the cellular exposition to imatinib $[49,50]$.

Resistance to imatinib turns up $2 \%$ to $4 \%$ a year. In the IRIS trial, the frequency was $3.3 \%$ in the first year, $7.5 \%$ in the second year, $4.8 \%$ in the third year, $1.5 \%$ in the fourth year, $0.8 \%$ in the fifth, $0.4 \%$ in the sixth; $1.4 \%$ in the seventh, and $1.3 \%$ in the eight year of treatment [51].

In case of failure, the use of second generation TKIs (like nilotinib and dasatinib) must be considered in the first place, but not when mutation T315I is present because it is resistant to both drugs.

If second generation TKIs are not available, imatinib $800 \mathrm{mg}$ may be administered, as well as its combination with other drugs. The second generation inhibitors have demonstrated to be more effective than high doses of imatinib; and they are associated with less adverse effects. However, CCRs may be obtained even in 50\%, particularly in patients who have had cytogenetic response before imatinib.

Failure may be classified according to the inability of reaching response or loss of any of the three responses: haematological, cytogenetic, and molecular.

The one with the worst prognosis is the haematological failure; thus, it must be changed to a second genera- tion TKI as soon as possible, as long as there is no mutation T315I. New therapies are being developed for this mutation [52].

In cases of cytogenetic failure (primary or secondary), timely intervention offers the best possibilities of a favourable outcome. Then, it is not recommended to continue with the same management and expect loss of haematological response.

The lack or loss of MMR is just a suboptimal response, not failure. There are no clinical data which support therapeutic changes in these cases, not even in cases of CMR. In our country, the use of cytogenetic response will be ideal as the main technique; nevertheless, molecular tests must be developed.

\subsection{Intolerance}

Intolerance is related to the presence of haematological or non-haematological adverse effects.

Most of the times, the secondary effects to imatinib are mild to moderate, grades 1 to 2 , and treated with symptomatic therapy, depending on the case. Adverse effects grade 1 to 2 must be treated; on the contrary, they may affect the long-term compliance. They must be timely solved to prevent, if possible, stopping imatinib treatment [53].

When toxicity was grade 3 to 4 , there are recommendations to solve it and to determine the moment when imatinib should be stopped temporarily or permanently [54]. As a rule, in cases of grades 3 or 4, the administration of imatinib is stopped. Therapy is reinitiated with $300 \mathrm{mg} /$ day or the same dose of $400 \mathrm{mg}$ when neutropenia or thrombocytopenia is solved in two weeks or less.

The adverse effects treatment depends on the grade of response of the patient, grade of toxicity, and availability of alternatives.

\subsection{Pharmacological Interactions}

Imatinib is metabolised in the liver, mainly by the P450, CY-P3A4 or CYP3A5 cytochrome enzymes. The drugs that induce increase of the group of enzymes CYP3A4/5 (like anticonvulsants and steroids) may reduce the imatinib therapeutic concentrations. On the contrary, drugs which inhibit CYP3A4 enzymatic activity (like clarithromycin and itraconazole) and the ones metabolized by CYP3A4/5 may cause high plasma levels of imatinib. Imatinib is also a mild inhibitor of the isoenzymes CYP2D6 and CYP2C9; thus, the drugs metabolized by these enzymes (like warfarin) must be used carefully.

In consequence, it is fundamental that in the assessment of toxicity and imatinib effectiveness, the potential pharmacological interactions be taken into account be- 
cause they may modify both efficacy and toxicity [46].

\subsection{Imatinib High doses as First-line Treatment}

Imatinib high doses and second generation of inhibitors have been studied as the first-line treatment for CML in chronic phase. In spite of achieving earlier responses with doses of $800 \mathrm{mg}$, nowadays, it cannot be affirm that this means better outcomes related to progression disease or survival because more follow-up is needed. This happens because of the frequency of interruptions and doses reductions when high doses are administered. Patients, who managed to keep a higher tolerability to the dose, seem to have a better long-term prognosis (Data from TIDEL, TOPS/24 months, and CML IV) [54-56].

Dose of $800 \mathrm{mg}$ is not recommended as first-line treatment in chronic phase.

Category of evidence: B. Recommendation grade: 1 (There is no unanimous consensus).

\subsection{Pregnancy}

Mesylate imatinib is teratogenic in animal models; then, a double-contraception in reproductive age women is recommendable. There are no concise treatment guidelines for pregnant patients who have CML and receive imatinib [46,55-57]. When there is suspicion of pregnancy or confirmation in women who receive imatinib, it is recommendable to immediately stop the treatment until the organogenesis has concluded (ending of the first quarter, approximately), and then begin with hydroxylurea or IFN- $\alpha$ until the pregnancy ends. If organogenesis has not concluded and blood count is required, an option is leukapheresis until chemotherapy may be applied with security. When pregnancy finishes, lactation must be prevented and begin treatment with imatinib, since $60 \%$ of the patients present an increase in $\mathrm{Ph}$ positive metaphases when they stop receiving imatinib [57].

In animal models, spermiogenesis may be damaged, but in the clinical experience, male fertility is preserved, although there are isolated reports of oligospermia [58].

An effective method of birth control is recommended to prevent pregnancy in women who receive imatinib. $P a$ tients who suspect pregnancy must not be administered imatinib or any other second generation kinase inhibitor. It must be consciously considered to continue treatment with these drugs, after the second quarter of pregnancy. A useful alternative is IFN- $\alpha$ or leukapheresis.

Category of evidence: B. Recommendation grade: 1 .

\subsection{Second Generation of TKI as First-line Treatment in Chronic Phase}

The activity of the second generation inhibitors nilotinib and dasatinib has been assessed as first-line treatment. Responses are superior to the historical control groups with $400 \mathrm{mg}$ and $800 \mathrm{mg}$ of imatinib.

Nilotinib is an oral tyrosine kinase inhibitor with a high specificity for BCR/ABL1 and potency 10 to 50 higher than imatinib to inhibit the proliferation and autophosphorylation of cell lines of BCR/ABL1 native type. It also inhibits 32 to 33 mutant cell lines of BCR/ABL1, but it is not effective in mutation T315I. It also inhibits the activity of Arg, Kit, and PDGFR, but not kinases in the family Src $[59,60]$.

The bioavailability of nilotinib increase with food (particularly the fatty ones); so, it should not be taken along with food.

Since phase II trials, results prove to be effective $[61,62]$. In a recent phase III trial, imatinib (dose 400 $\mathrm{mg} /$ day) was compared to nilotinib (150 mg/BID), or 200 $\mathrm{mg}$. Albeit the results with nilotinib were not so good like in the phase II trials, that does demonstrate better efficacy with both doses. There was no significant difference in adverse effects $[63,64]$.

Dasatinib is a dual oral tyrosine kinase inhibitor with an in vitro potency of about 300 times higher than imatinib to inhibit the proliferation and autophosphorylation of BCR/ABL1 cell lines native type, as well as most of the BCR/ABL1 mutations, except T315I. It also inhibits the Scr family, among others.

Likewise, the results of dasatinib in phase II trials are promising [57]. In the latest phase III trial, imatinib (400 $\mathrm{mg} /$ day $)$ is randomly compared against dasatinib $(100 \mathrm{mg}$ every 24 hours). Like in the nilotinib trial, the results were not so satisfactory like the phase III trials, but dasatinib was more effective than imatinib [64].

TKIs showed faster and better responses (for instance, MMR at 12 months) than imatinib, until the publication of the phase III trials.

Due to the celerity and scope of the response to the second generation TKIs, it is possible that in a future, the proposed response criteria for imatinib change and new criteria come into view for the second generation of TKIs in first line.

The adverse effects are less common when dasatinib or nilotinib are administered in first line than in second one (see security profile in TKIs in second line). However, cardiotoxicity must be assessed, as well as the QTc interval.

It is recommended to consider nilotinib or dasatinib as the first line treatment for CML in chronic phase, recently diagnosed. Nilotinib recommended dose is $300 \mathrm{mg}$ every 12 hours, 2 hours before and one hour after meals. Dasatinib recommended dose is $100 \mathrm{mg}$ every 24 hours.

Choosing among imatinib, nilotinib or dasatinib must be personalized according to age, disease risk, comorbidity, security profile, cost, and availability.

Nilotinib and dasatinib have been approved in Mexico as first-line treatment. 
Category of evidence: A. Recommendation grade: 1 .

\subsection{Second-Line Treatment. CML in Chronic Phase (Resistant or Intolerant to Imatinib)}

Second line tyrosine kinase inhibitors as second-line treatment. Resistance or primary failure to reach haematological response (at three months) or cytogenetic one (some grade al 6 months) is rare with the administration of imatinib.

Primary or secondary resistance to imatinib causes therapeutic failure, which is present in $15 \%-25 \%$ of the patients. In the IRIS trial, $14 \%$ had poor therapeutic effect in the 8-year follow-up.

According to the molecular perspective, the secondary resistance is the result of the stimulation of the BCR/ ABL activity; nevertheless, it happens because of the poor compliance to imatinib treatment. Therefore, before switching to a second generation TKIs, the compliance should be assessed in order to find if it is causing a wrong response.

Intolerance to imatinib may cause stopping its administration, even in $5 \%$ of the patients, as it has happened in the IRIS trial, after an 8-year follow-up.

Both dasatinib (approved by the FDA in June 2006) and nilotinib (approved by the FDA in October 2007) have demonstrated to be very potent and effective drugs for patients resistant or intolerant to imatinib. Both are available in Mexico.

Dasatinib. At the beginning, the dose was $70 \mathrm{mg}$ every 12 hours and the responses were good $[59,60,64]$. Then, a phase III trial was carried out to establish the optimal dose. It was demonstrated that each $100 \mathrm{mg}$ every 24 hours have the same efficacy, but less adverse effects $[65$, 66].

Taking that into account, dasatinib optimal dose is 100 $\mathrm{mg}$ (once a day) in the chronic phase [67].

Nilotinib. In chronic phase, the nilotinib optimal dose is $400 \mathrm{mg} / \mathrm{BID}$ and has been confirmed in phase II trials $[57,68,69]$.

In Mexico (October 2006), the Compassionate Access Program (CAP) began [64]. It enabled the generation of a national experience in patients with $\mathrm{CML} \mathrm{Ph}$ positive, resistant or intolerant to imatinib in chronic, accelerated or blastic phases with 57 patients in Mexico, out of a 940. Most of them $(60 \%)$ had progressed to an accelerated phase $(45 \%)$ or blastic $(15 \%)$. The CHR rate was $79 \%$ with a CCR of $23 \%$, and a MR of $10 \%$. The detected basal mutations included E355G, T315I, M351T, F359V/F, F317L, F486S/F, G250E, M315T/M, E453K, and $\mathrm{F} 486 \mathrm{~S} / \mathrm{F}$ in $13(32 \%)$ of the patients [70,71].

The results with dasatinib and nilotinib have been quite satisfactory as rescue treatment or second line in patients with failure or intolerance to imatinib. The re- sponse is better after intolerance rather than after failure with imatinib. In most of the cases, the response is longlasting.

Usually, there is no crossed intolerance between imatinib and the second generation TKIs with respect to non haematological effects. Nevertheless, there is a certain degree of crossed toxicity for the haematological toxicity (tendency to develop cytopenias).

The adverse effects may have different profiles in dasatinib (mainly in lungs), compared with nilotinib (in pancreas, increase in billirubin level, and rash), but there is a potential of cardiotoxicity risk with both of them, besides a prolongation of QT interval. Thus, the treatment must be personalized according to every patient's status related to these clinical conditions.

There are criteria for the treatment of adverse effects with dasatinib and nilotinib, the same happens with imatinib.

Choosing one or another drug depends on the availability and cost evaluation. With respect to efficacy, informed results with both are similar; there are just some mutations which are more sensitive to one or another drug. These in vitro data may or not correlate with the clinical response in the patients, with the exception of mutation T315I which implies resistance to TKIs [72].

What must be evaluated, to choose the best option, is every drug security profile in relation to background and comorbidity in every patient.

The second generation of TKIs is less dependent of transporters. For instance, they do not depend on OCT-1. Nevertheless, they are also metabolized in the hepatic microsomal system and present pharmacological interacttions which may modify their efficacy or security profile.

It is recommended to have those interactions at close hand during the treatment with TKIs.

It is recommended to administer dasatinib $100 \mathrm{mg} /$ daily, along with or without food.

Nilotinib is recommended $400 \mathrm{mg} /$ BID. Tablets must be taken two hours before and one hour after meals.

So far, availability and costs of these drugs limited their use in Mexico. Taking the decision of administering one or another must be individual, because there is a lack of a trial which compares them prospective and directly [55].

Category of evidence: B. Recommendation grade: 1.

\subsection{Treatment Adjustment According to Response}

The definitions of suboptimal response are only applicable to imatinib and according to European Leukemia Net; for NCCN only complete and partial responses are assessed in the use of second generation inhibitors $[58,73]$.

It is recommended that patients under dasatinib or ni- 
lotinib treatment in chronic phase must continue with clinical control and serial CBC every two weeks until the stabilization of the counting takes place; after CHR, every four weeks; and after CCR every six weeks. Patients must undergo liver function tests twice a week during four weeks, then every six weeks.

Evaluation of the second generation TKIs response must be carried out earlier because their efficacy (or resistance) is evident prematurely. Therefore, it is recommended to perform the first cytogenetic assessment in bone marrow at three months. Likewise, evaluation of the $B C R / A B L$ transcripts, by means of QTR-PCR in real time, must be carried out at three months because it has a prognostic value. [74].

Category of evidence: A. Recommendation grade: 1

When there is failure or suboptimal response to second generation TKIs during treatment, HCT must be considered [75]. There are criteria to early evaluate the response to these drugs and to decide if the patient should undergo HCT.

Category of evidence: A. Recommendation grade: 1.

\subsection{Imatinib High Doses as Second-Line Treatment}

The results of imatinib at high doses as second-line treatment are not as good as the ones with second generation TKIs. The cause of that are adverse effects of imatinib high doses (see imatinib high doses in first-line treatment).

Nevertheless, in cases of suboptimal response or failure (when there is no access to second generation of TKIs), high doses of imatinib must be regarded either by lack of them or by their high cost. Ideally, in case of failure, mutations must be carried out in order to demonstrate the presence of a non-sensitive mutation like T315I.

\section{Transplantation}

The allogenic stem cell transplantation (ASCT) is the potentially curative treatment for CML; nevertheless, the excellent outcomes with first and second TKIs have placed this treatment as a second alternative.

The outcomes with ASCT in chronic phase are quite superior to advanced and blastic phases. In the era of TKIs, survival after transplantation in patients in chronic phase is $91 \%$ at three years globally. When they are classified by risk, according to the European Group for Blood Marrow Transplantation (EBMT) is $88.2 \%, 94 \%$, and 59\% for groups I, II, and III, respectively [76].

The results of International Blood and Marrow Transplantation (IBMTR) from 1998 to 2008 showed that the survival at three years is $70 \%-72 \%$ for patients in chronic phase; $45 \%-56 \%$ for patients in accelerated phase, and $16 \%$ for patients in blastic phase [77].

\subsection{Donors Search for Bone Marrow Transplantation}

The next patients are regarded high risk; then, it is necessary to look for HLA-compatible donors.

- Chronic phase with high Sokal;

- Low Sokal with therapeutic failure to the first-line TKIs;

- Identify the patients with therapeutic failure to TKIs to take them to second-line treatment and who have poor risk, according to the Hammersmith index [78];

- Patients who reach accelerated and blastic phase.

\subsection{Indications for Transplantation}

Chronic phase [79]:

- Patients with failure to the first-line with TKIs or who are being assessed for the response to second generation TKIs (see criteria response in indications for second line).

- Nowadays, ASCT is an excellent option as first-line treatment when patients are in accelerated and blastic phases at diagnosis, and have mutation T315I, patients with intolerance or failure to TKIs.

Advanced disease [79]:

- Accelerated phase: patients with failure to second generation TKI.

Blastic phase [79]:

- Patients who experience complete remission to the induction protocol with QT alone or TKI.

Conditioning protocols [80]:

- Busulfan/cyclophosphamide in patients who require myeloablative protocols;

- Fludarabine/cyclophosphamide in patients who need reduced intensity protocol.

\subsection{Post-Transplantation Treatment}

Use of Donor Lymphocyte Infusion (DLI) after transplantation. Patients who underwent a reduced intensity protocol, do not have Graft-versus-host-disease, and present haematological and/or cytogenetic relapse may reach remission in $60 \%$ - 90\% with the lymphocyte infusion. When choosing this treatment, it is recommended to adjust the dose [81].

Monitoring of minimal residual disease after transplantation. Several relapses have been observed after donor allogenic transplantation related to chronic phase of CML in $8 \%$ to $26 \%$.

The lymphocyte infusion, imatinib induction, and elimination of immunosuppression are some alternatives to relapse after ASCT.

The level of the transcript BCR/ABL1 predicts re- 
sponse to TKIs and relapse possibility with these treatments. Although the kinetics of transcript BCR/ABL1 after transplantation has not been examined, some studies have suggested that the increase in the transcript levels - before the transplantation - predict relapse.

A molecular monitoring must be performed by means of qRT-QRT-PCR technique, in the months 1, 2, 3, 6, 9, and 12. Later on, every six months, minimal residual disease must be considered in case of:

- $\mathrm{BCR} / \mathrm{ABL} 1 / \mathrm{ABL}>0.02 \%$ in three monthly tests.

- $\mathrm{BCR} / \mathrm{ABL} 1 / \mathrm{ABL}>0.05 \%$ in two monthly tests.

Nevertheless, there is no international standardization for monitoring. Additionally, conventional chromosomal study and FISH must be carried out.

TKIs after transplantation. The beginning of the TKIs treatment will depend on several factors and clinical status of the patient after transplantation, as conditioning protocol, immunosupressor drug, infectious complications, and persistence of transcript $\mathrm{BCR} / \mathrm{ABL}$ (minimal residual disease).

The patient will begin TKIs when the complete immunosuppression was stopped, as long as the minimal residual disease is not informed. In case of presence of minimal residual disease, TKIs must be administered [82].

\section{Advanced Phases Treatment (Accelerated and Blastic)}

\subsection{Accelerated Phase}

The definition of the accelerated phase may be controversial (see Phases and Definitions). The most used definition is the WHO one. The treatment depends on the progression (or absence of it) to these phases in presence of a TKI [56-59]. The results shown with dasatinib and nilotinib occurred in patients resistant or intolerant to imatinib.

1) First line. When there has not been previous treatment with TKIs, imatinib $600 \mathrm{mg}$ to $800 \mathrm{mg} /$ day is recommended, followed by ASCT [83].

2) In case of resistant mutations to imatinib, nilotinib 400 mg every 12 hours or dasatinib 140 every 24 hours [84].

Second line. In case of previous treatment with imatinib, ASCT is recommended, followed by dasatinib or nilotinib at the aforementioned doses.

As it was discussed, in patients with CML in advanced phases, the possibility of allogenic stem cell transplantation must be considered (ASCT) [85].

Recommendation in Mexico. The first-line treatment in patients with CML in accelerated phase may be imatinib $600 \mathrm{mg} /$ day, followed by ASCT. When the second generation of TKIs are available, dasatinib and nilotinib are recommended, followed by ASCT.
Category of evidence: B. Recommendation grade: 1.

\subsection{Blastic Phase}

In the blastic phase, global responses are obtained with imatinib from $55 \%$ to $70 \%$, with complete responses of $11 \%-20 \%$ of these patients [86].

1) In a II phase trial of CML in blastic phase (myeloid phenotype $=74$ and lymphoid $=42$ patients) with an 8month follow-up, dasatinib induced haematological responses in $33 \%$ and $31 \%$, and cytogenetic remissions higher in $31 \%$ and $50 \%$, respectively. However, only $31 \%$ and $13 \%$ of the patients remain in the same follow-up [87].

Nilotinib. In phase II trials of CML in myeloid and lymphoid phases, nilotinib showed CHR in $11 \%$ and $13 \%$, respectively; in CCR $29 \%$ and $32 \%$, respectively [88].

Given that in the three TKIs the responses in blastic phase are rather brief; chemotherapy (lymphoid or myeloid) is recommended, depending on the corresponding cell lineage [89].

An ASCT must be regarded as consolidation therapy.

Imatinib $600 \mathrm{mg}$ - $800 \mathrm{mg} /$ day + suitable chemotherapy. Dasatinib $70 \mathrm{mg} / \mathrm{BID}+$ suitable chemotherapy

Category of evidence: B. Recommendation grade: 1 .

In Mexico, the combination of imatinib $600 \mathrm{mg}$ to 800 mg or a second generation of TKIs (dasatinib or nilotinib) is recommended for patients with blastic phase of the CML. Such treatments are associated with the corresponding chemotherapy to the leukaemia phenotype (lymphoid or myeloid), followed by allogenic stem cell transplantation.

Category of evidence: B. Recommendation grade: 1 .

\section{Acknowledgements}

The authors of the Mexican Guidelines for the Diagnosis and Treatment of Chronic Myeloid Leukaemia would like to state our acknowledgment to Bristol-Myers Squibb for the support given to the consensus.

\section{REFERENCES}

[1] M. Baccarani, J. E. Cortés, F. Pane, D. Niederiwieser, G. Saglio, J. Apperley, F. Cervantes, M. Deininger, A. Gratwohl, F. Guilhot, A. Hochhaus, M Horowitz, T. Hughes, H. Kantarjian, R. Larson, J. Radich, B. Simonsson, R. T. Silver, J. Goldman and R. Hehlmann, "Chronic Myeloid Leukemia: An Update of Concepts and Management Recommendations of European Leukemia Net," Journal of Clinical Oncology, Vol. 27, No. 35, 2009, pp. 6041-6051. doi:10.1200/JCO.2009.25.0779

[2] National Comprehensive Cancer Network (NCCN), "NCCN Practice Guidelines in Oncology Chronic Myeloid Leukemia, V3," 2008. 
http://www.nccn.org/professionals/physician_gls/f_guidel ines.asp

[3] J. F. Combariza, M. L. Rodríguez, J. García, M. Acevedo de los Ríos, K. Gálvez, A. Cardona, I. Munévar, M. González, C. Casas, J. O. Pacheco, L Enciso, M. V. Herrera, F. Galeano, F. Durango, C. Niño, M. Rosales, M.Piña, C. Rosales, V. Abello, J. Guerra, E. Cantor, J. Rosales, M. Daza de Bojanini, C. Sossa, A. Camacho, C. Castro and J. Duque, "Diagnosis and Treatment Consensus of Chronic Myeloid Leukemia in Colombia," Revista Colombiana de Cancerología, Vol. 12, No. 3, 2008, pp. 126-142.

[4] M. Nese, G. Acosta, M. Bengochea, B. Beñarán, E. Bodega, R. Bonimi, G. Borelli, M. Bruzone, L. Camacho, A. Caneiro, C. Canessa and A. Cardessa, "National Consensus of Chronic Myeloid Leukemia," Hematología (Montev. en línea), Vol. 1, No. 3, 2005, pp. 28-41.

[5] J. Alfaro-Lucero, P. Cortés-Monroy-Bertín, M. E. CabreraContreras, C. Cao-Pochintesta, G. Conte-Lanza and P. Fardella-Besto, "Minimun Clinic Recommendations for the Study and Treatment of Chronic Myeloid Leukemia (CML)," Sociedad Chilena de Hematología, Santiago, 2008.

[6] H. J. Schünemann, A. D. Oxman, et al., "GRADE: Grading Quality of Evidence and Strength of Recommendations for Diagnostic Tests and Strategies," British Medical Journal, Vol. 336, 2008, pp. 1106-1110. doi:10.1136/bmj.39500.677199.AE

[7] A. Jemal, R. Siegel, J. Xu and E. Ward, "Cancer Statistics 2010," CA: A Cancer Journal for Clinicians, Vol. 60, No. 5, 2010, p. 277. doi:10.3322/caac.20073

[8] S. F. Altekruse, C. L. Kosary, M. Krapcho, N. Neyman, R. Aminou and W. Waldron, "SEER Cancer Statistics Review, 1975-2007, National Cancer Institute,” 2009. http://seer.cancer.gov/csr/1975_2007/

[9] A. Aguayo, E. García-Álvarez, Y. Cázarez-Ordóñez, E. Crespo-Solís, D. Martínez-Baños, E. Guadarrama-Beltrán, E. E. Cervera-Ceballos and X. López-Karpovicth. "Chronic Myeloid Leukemia: A Clinicoepidemiologic and Therapeutic Description of a Single Institution in México City," Clinical Leukemia, Vol. 2, No. 4, 2008, pp. 261-266. doi:10.3816/CLK.2008.n.036

[10] O. G. Cantú-Rodríguez, C. H. Gutiérrez-Aguirre and O. González-Llano. "La Leucemia Granulocítica Crónica se Presenta a una Edad más Temprana a la Reportada en Otros Países en los Pacientes de un Hospital de Concentración en México," Review of Hematology, Vol. 9, No. 2, 2008, pp. S47-S134.

[11] P. Vargas-Viveros, R. Hurtado Monroy, E. Cervera, C. Best, A. Aguayo and M. Candelaria, "The Age of Mexican Patients with Chronic Myeloid Leukemia (CML) Ph Positive Is Quite Younger."

[12] M. Rohrbacher and J. Hasford, "Epidemiology of Chronic Myeloid Leukaemia," Best Practice \& Research Clinical Haematology, Vol. 22, No. 3, 2009, pp. 295-302. doi:10.1016/j.beha.2009.07.007

[13] J. Sessions, "Chronic Myeloid Leukemia in 2007," Journal of Managed Care Pharmacy, Vol. 13, No. 8, 2007, pp. S4-S7.
[14] J. E. Cortes, M. Talpaz, S. O’Brian, S. Faderl, G. GarcíaManero, A. Ferrajoli, S. Verstovsek, M. B. Rios, J. Shan and H. M. Kantarjian, "Staging of Chronic Myeloid Leukemia in the Imatinib Era," Cancer, Vol. 106, No. 6, 2006, pp. 1306-1315. doi:10.1002/cncr.21756

[15] H. M. Kantarjian, M. J. Keating, T. L. Smith, M. Talpaz and K. B. McCredie, "Proposal for a Simple Synthesis Prognostic Staging System in Chronic Myelogenous Leukemia," The American Journal of Medicine, Vol. 88, No. 1, 1990, pp. 1-8. doi:10.1016/0002-9343(90)90119-X

[16] F. Castagnetti, N. Testoni, S. Luatti, G. Marzocchi, M. Mancini, S. Kerim, E. Giugliano, F. Albano, A. Cuneo, E. Abruzzese, B. Martino, F. Palandri, M. Amabile, I. Iacobucci, G. Alimena, F. Pane, G. Martinelli, G. Saglio, M. Baccarani and G. Rosti, "Deletions of the Derivative Chromosome 9 Do Not Influence the Response and the Outcome of Chronic Myeloid Leukemia in Early Chronic Phase Treated with Imatinib Mesylate: GIMEMA CML Working Party Analysis," Journal of Clinical Oncology, Vol. 28, No. 16, 2010, pp. 2748-2754. doi:10.1200/JCO.2009.26.7963

[17] P. C. Nowell and D. A. Hungerford, "A Minute Chromosome in Human Chronic Granulocytic Leukemia," Science, Vol. 132, 1960, p. 1497.

[18] R. Bernstein, "Cytogenetics of Chronic Myelogenous Leukemia," Seminars in Hematology, Vol. 25, No. 1, 1988, pp. 20-34.

[19] A. Quintas-Cardama and J. Cortés, "Molecular Biology of BCR/ABL1 Positive Chronic Myeloid Leukemia," Blood, Vol. 113, No. 8, 2009, pp. 1619-1630. doi:10.1182/blood-2008-03-144790

[20] N. Heisterkamp, G. Jenster, J. Hoeve, D. Zovich, P. K. Pattengale and J. Groffen, "Acute Leukaemia in BCR/ABL Transgenic Mice,” Nature, Vol. 344, No. 6263, 1990, pp. 251-253. doi:10.1038/344251a0

[21] J. Cortes, D. W. Kim, E. Raffoux, G. Martinelli, E. Ritchie, L. Roy, S. Coutre, S. Corm, N. Hamerschlak, J. L. Tang, A. Hochhaus, H. J. Khoury, T. H. Brümmendorf, M. Michallet, G. Rege-Cambrin, C. Gambacorti-Passerini, J. P. Radich, T. Ernst, C. Zhu, J. M. Van Tornout and M. Talpaz, "Efficacy and Safety of Dasatinib in Imatinib Resistant or Intolerant Patients with Chronic Myeloid Leukemia in Blast Phase," Leukemia, Vol. 22, No. 12, 2008, pp. 2176-2183. doi:10.1038/leu.2008.221

[22] M. L. Gishizky and O. N. Witte, "Initiation of Deregulated Growth of Multipotent Progenitor Cells by BCR/ABL1 in Vitro," Science, Vol. 256, No. 5058, 1992, pp. 836-839. doi:10.1126/science. 1375394

[23] K. Nishii, J. H. Kabarowski, D. L. Gibbons, S. D. Griffiths, I. Titley, L. M. Wiedemann and M. F. Greaves, "Ts BCR/ABL1 Kinase Activation Confers Increased Resistance to Genotoxic Damage via Cell Cycle Block," Oncogene, Vol. 13, 1996, pp. 2225-2234.

[24] C. A. Evans, P. J. Owen-Lynch, A. D. Whetton and C. Dive, "Activation of the Abelson Tyrosine Kinase Activity Is Associated with Suppression of Apoptosis in Hemopoietic Cells," Cancer Research, Vol. 53, 1993, pp. 1735-1738.

[25] G. Bazzoni, N. Carlesso, J. D. Griffin and M. E. Hemler, 
"BCR/ABL Expression Stimulates Integrin Function in Hematopoietic Cell Lines," The Journal of Clinical Investigation, Vol. 98, No. 2, 1996, pp. 521-528. doi:10.1172/JCI118820

[26] M. Y. Gordon, C. R. Dowding, G. P. Riley, J. M. Goldman and M. F. Greaves, "Altered Adhesive Interactions with Marrow Stroma of Haematopoietic Progenitor Cells in Chronic Myeloid Leukaemia," Nature, Vol. 328, No. 6128, 1987, pp. 342-344. doi:10.1038/328342a0

[27] R. Bhatia, J. B. McCarthy and C. M. Verfaillie, "Interferon-Alpha Restores Normal Beta 1 Integrin-Mediated Inhibition of Hematopoietic Progenitor Proliferation by the Marrow Microenvironment in Chronic Myelogenous Leukemia," Blood, Vol. 87, No. 9, 1996, pp. 3883-3891.

[28] R. A. Van Etten, P. Jackson and D. Baltimore, "The Mouse Type IV c-ABL Gene Product Is a Nuclear Protein, and Activation of Transforming Ability Is Associated with Cytoplasmic Localization," Cell, Vol. 58, No. 4, 1989, pp. 669-678.

[29] J. M. Lewis, R. Baskaran, S. Taagepera, M. A. Schwartz and J. Y. J. Wang. "Integrin Regulation of c-ABL Tyrosine Kinase Activity and Cytoplasmic-Nuclear Transport," Proceedings of the National Academy of Sciences of USA, Vol. 93, No. 26, 1996, pp. 15174-15179. doi:10.1073/pnas.93.26.15174

[30] G. L. Nichols, M. A. Raines, J. C. Vera, L. Lacomis, P. Tempst and D. W. Golde, "Identification of CRKL as the Constitutively Phosphorylated 39-kD Tyrosine Phosphoprotein in Chronic Myelogenous Leukemia Cells," Blood, Vol. 84, No. 9, 1994, pp. 2912-2918.

[31] T. Oda, C. Heaney, J.R. Hagopian, K. Okuda, J. D. Griffin and B. J. Druker, "Crkl Is the Major Tyrosine-Phosphorylated Protein in Neutrophils from Patients with Chronic Myelogenous Leukemia," The Journal of Biological Chemistry, Vol. 269, No. 37, 1994, pp. 2292522928.

[32] W. N. M. Deininger, J. M. Goldman and J. V. Melo, "The Molecular Biology of Chronic Myeloid Leukemia," Blood, Vol. 96, No. 10, 2000, pp. 3343-3356.

[33] R. Ruibao. Mechanisms of BCR-ABL in the Pathogenesis of Chronic Myelogenous Leukaemia," Nature Reviews Cancer, Vol. 5, 2005, pp. 172-183. doi:10.1038/nrc1567

[34] F. H. Epstein, S. Faderl, M. Talpaz, Z. Estrov, S. O’Brien, R. Kurzrock and H. M. Kantarjian, "The Biology of Chronic Myeloid Leukemia," New England Journal of Medicine, Vol. 341, No. 3, 1999, pp. 164-172. doi:10.1056/NEJM199907153410306

[35] Y. Chen, C. Peng, D. Li and S. Li, "Molecular and Cellular Bases of Chronic Myeloid Leukemia," Protein \& Cell Vol. 1, No. 2, 2010, pp. 124-132. doi:10.1007/s13238-010-0016-Z

[36] M. Baccarani, F. Pane and G. Saglio, "Monitoring Treatment of Chronic Myeloid Leukemia," Haematologica, Vol. 93, No. 2, 2008, pp. 161-166. doi:10.3324/haematol.12588

[37] D. P. Steensma and R. E. Richard, "Myeloproliferative Disorders. En: American Society of Hematology SelfAssessment Program. Textbook," In: M. J. Kahn and S. A.
Gregory, Eds., The American Society of Hematology, 3rd Edition, Washington DC, 2007, pp. 172-227.

[38] C. E. Bueso-Ramos, J. E. Cortés, M. Talpaz, S. O’Brien, F. Giles, M. B. Ríos, L. J. Medeiros and H. Kantarjian, "Imatinib Mesylate Therapy Reduces Bone Marrow Fibrosis in Patients with Chronic Myelogenous Leukemia," Cancer, Vol. 101, No. 2, 2004, pp. 332-336. doi: $10.1002 /$ cncr. 20380

[39] T. P. Hughes, J. Kaeda, S. Brandford, Z. Rudzki, A. Hochhaus, M. L. Hensley, I. Gathmann, A. E. Bolton, I. C. van Hoomissen, J. M. Goldman and J. P. Radich, "International Randomised Study of Interferon versus STI571 (IRIS) Study Group. Frequency of Major Molecular Response to Imatinib or Interferon Alpha Plus Cytarabine in Newly Diagnosed Chronic Myeloid Leukemia," The New England Journal Medicine, Vol. 349, No. 15, 2003, pp. 1423-1432. doi:10.1056/NEJMoa030513

[40] A. Hochhaus, S. G. O’Brien, F. Guilhot, B. J. Druker, S. Brandford, L. Foroni, J. M. Goldman, M. C. Müller, J. P. Radich, M. Rudoltz, M. Mone, I. Gathmann, T. P. Hughes and R. A. Larson, "IRIS Investigators. Six-Year Follow-Up of Patients Receiving Imatinib for the FirstLine Treatment of Chronic Myeloid Leukemia," Leukemia, Vol. 23, No. 6, 2009, pp. 1054-1061. doi:10.1038/leu.2009.38

[41] B. J. Druker, F. Guilhot, S. G. O’Brien, I. Gathmann, H. Kantarjian, N. Gattermann, M. W. Deininger, R. T. Silver, J. M. Goldman, R. M. Stone, F. Cervantes, A. Hochhaus, B. L. Powell, J. L. Gabrilove, P. Rousselot, J. Reiffers, J. J. Cornelissen, T. Hughes, H. Agis, T. Fischer, G. Verhoef, J. Shepherd, G. Saglio, A. Gratwohl, J. L. Nielsen, J. P. Radich, B. Simonsson, K. Taylor, M. Baccarani, C. So, L. Letvak and R. A. Larson, "IRIS Investigators. FiveYear Follow-Up of Patients Receiving Imatinib for Chronic Myeloid Leukemia," The New England Journal Medicine, Vol. 355, No. 23, 2006, pp. 2408-2417. doi:10.1056/NEJMoa062867

[42] Y. Zhao, L. Liu, Y. Wang, G. Wu, X. Lai, W. Cao, Y. Luo, Y. Tan, J. Shi, W. Xie, X. Ye, Z. Cai, M. Lin and H. Huang, "Efficacy and Prognosis of Chronic Myeloid Leukemia Treated with Imatinib Mesylate in a Chinese Population," International Journal of Hematology, Vol. 89, No. 4, 2009, pp. 445-451. doi:10.1007/s12185-009-0292-7

[43] M. W. N. Deininger, J. E. Cortes, R. Paquette, B. Park, A. Hochhaus, M. Baccarani, R. Stone, T. Fischer, H. Kantarjian, D. Niederwieser, C. Gambacorti-Passerini, C. So, I. Gathmann, J. M. Goldman, D. Smith, B. J. Druker and F. Guilhot, "The Prognosis for Patients with Chronic Myeloid Leukemia Who have Clonal Cytogenetic Abnormalities in Philadelphia Chromosome-Negative Cells," Cancer, Vol. 110, No. 7, 2007, pp. 1509-1519. doi:10.1002/cncr.22936

[44] M. W. Deininger, S. G. O'Brien, J. M. Foerd and B. J. Drucker, "Practical Management of Patients with Chronic Myeloid Leukemia Receiving Imatinib," Journal of Clinical Oncology, Vol. 21, No. 8, 2003, pp. 1637-1647. doi:10.1200/JCO.2003.11.143

[45] L. G. Shaffer and N. Tommerup, "ISCN 2009 BASEL, International Standing Committee on Human Cytogenet- 
ics Nomenclature," Karger Press, Switzerland, 2009.

[46] T. P. Hughes, A. Hochhaus, S. Branford, M. C. Muller, J. S. Kaeda and L. Foroni, "Long-Term Prognostic Significance of Early Molecular Response to Imatinib in Newly Diagnosed Chronic Myeloid Leukemia: An Analysis from the International Randomized Study of Interferon and STI571 (IRIS)," Blood, Vol. 116, No. 19, 2010, pp. 3758-3765. doi:10.1182/blood-2010-03-273979

[47] M. Baccarani, G. Saglio, J. Goldman, A. Hochhaus, B. Simonsson, F. Appelbaum, J. Apperley, F. Cervantes, J. Cortes, M. Deininger, A. Gratwohl, F. Guilhot, M. Horowitz, T. Hughes, H. Kantarjian, R. Larson, D. Niederwieser, R. Silver and R. Hehlmann, "European Leukemia Net. Evolving Concepts in the Management of Chronic Myeloid Leukemia: Recommendations from an Expert Panel on Behalf of the European Leukemia Net," Blood, Vol. 108, No. 6, 2006, pp. 1809-1820. doi:10.1182/blood-2006-02-005686

[48] Y. Alvarado, H. Kantarjian, S. O'Brien, S. Faderl, G. Borthakur, J. Burger, W. Wierda, G. Garcia-Manero, J. Shan and J. Cortes, "Significance of Suboptimal Response to Imatinib, as Defined by the European Leukemia Net, in the Long-Term Outcome of Patients with Early Chronic Myeloid Leukemia in Chronic Phase," Cancer, Vol. 115, No. 16, 2009, pp. 3709-3718. doi: $10.1002 /$ cncr. 24418

[49] S. Richebourg, V. Eclache, C. Perot, M. F. Portnoi, J. van den Akker, C. Terré, O. Maareck, V. Soenen, F. Viguié, J. L. Laï, J. Andrieux, S. Corm and C. Roche-Lestienne, "Fi-LMC Group. Mechanisms of Genesis of Variant Translocations in Chronic Myeloid Leukemia Are not Correlated with ABL or BCR Deletion Status or Response to Imatinib Therapy," Cancer Genetics and Cytogenetics, Vol. 182, No. 2, 2008, pp. 95-102. doi:10.1016/j.cancergencyto.2008.01.005

[50] D. Marin, D. Milojkovic, E. Olavarria, J. S. Khorashad, H. de Lavallade, A. G. Reid, L. Foroni, K. Rezvani, M. Bua, F. Dazzi, J. Pavlu, M. Klammer, J. S. Kaeda, J. M. Goldman and J. F. Apperley, "European Leukemia Net Criteria for Failure or Suboptimal Response Reliably Identify Patients with CML in Early Chronic Phase Treated with Imatinib Whose Eventual Outcome is Poor," Blood, Vol. 112, No. 12, 2008, pp. 4437-4444.

doi:10.1182/blood-2008-06-162388

[51] S. O'Brien, F. Guilhot and J. Goldman, "International Randomized Study of Interferon versus STI571 (IRIS) 7-Year Follow-up: Sustained Survival, Low Rate for Transformation and Increased Rate of Major Molecular Response (MMR) in Patients (pts) with Newly Diagnosed Chronic Myeloid Leukemia in Chronic Phase (CML-CP) Treated with Imatinib (IMATINIB)," Blood, Vol. 112, 2008.

https://ash.confex.com/ash/2008/webprogram/Paper1405 7.html

[52] R. Carlson, "Ponatinib Effective in Heavily Pretreated CML Patients with T3151 Mutation," Oncology Times, Vol. 8, No. 3, 2011, pp. 17-18. doi:10.1097/01.COT.0000405236.49243.3b

[53] H. M. Kantarjian, J. E. Cortes, P. La Roseé and A. Hochhaus, "Optimizing Therapy for Patients with Chro- nic Myeloid Leukemia in Chronic Phase," Cancer, Vol. 116, No. 6, 2010, pp. 1419-1430.

doi: $10.1002 /$ cncr. 24928

[54] R. Hehlmann, S. Saussele, M. Lauseker, P. Ulrike, E. Kovalevskaya, A. Leitner, C. Haferlach, B. Schlegelberger, M. C. Müller, B. Hanfstein, M. Pfirrmann, G. Ehninger, T. Fischer, J. Hasford, A. Hochhaus, D. K. Hossfeld, H. J. Kolb, S. W. Krause, C. Nerl, H. Pralle, A. Gratwohl, A. Tobler and H. Heimpel, "The German CML Study Group. Randomized Comparison of Imatinib 400 mg vs. Imatinib + IFN vs. Imatinib + araC vs. Imatinib after IFN vs. Imatinib $800 \mathrm{mg}$ : Optimized Treatment and suRvival: Designed First Interim Analysis of the German CML Study IV [abstract]," Blood, Vol. 112, 2008.

https://ash.confex.com/ash/2008/webprogram/Paper1405 7.html

[55] T. P. Hughes, S. Branford, D. L. White, J. Reynolds, R. Koelmeyer, J. F. Seymour, K. Taylor, C. Arthur, A. Schwarer, J. Morton, J. Cooney, M. F. Leahy, P. Rowlings, J. Catalano, M. Hertzberg, R. Filshie, A. K. Mills, K. Fay, S. Durrant, H. Januszewicz, D. Joske, C. Underhill, S. Dunkley, K. Lynch and A. Grigg, "Australasian Leukaemia and Lymphoma Group. Impact of Early Dose Intensity on Cytogenetic and Molecular Responses in Chronic-Phase CML Patients Receiving $600 \mathrm{mg}$ /day of Imatinib as Initial Therapy," Blood, Vol. 112, No. 10, 2008, pp. 3965-3973. doi:10.1182/blood-2008-06-161737

[56] J. E. Cortes, M. Baccarani, F. Guilhot, B. J. Druker, S. Brandford, D. W. Kim, F. Pane, R. Pasquini, S. L. Goldberg, M. Kalaycio, B. Moiraghi, J. M. Rowe, E. Tothova, C. De Souza, M. Rudoltz, R. Yu, T. Krahnke, H. M. Kantarjian, J. P. Radich and T. P. Hughes, "Phase III, Randomized, Open-Label Study of Daily Imatinib Mesylate $400 \mathrm{mg}$ versus $800 \mathrm{mg}$ in Patients with Newly Diagnosed, Previously Untreated Chronic Myeloid Leukemia in Chronic Phase Using Molecular End Points: Tyrosine Kinase Inhibitor Optimization and Selectivity Study," Journal Clinical Oncology, Vol. 28, No. 3, 2010, pp. 424430. doi:10.1200/JCO.2009.25.3724.

[57] S. M. Pye, J. E. Cortes, P. Ault, A. Hatfield, H. Kantarjian, R. Pilot, G. Rosti and J. F. Apperley, "The Effects of Imatinib on Pregnancy Outcome," Blood, Vol. 111, No. 12, 2008, pp. 5505-5508. doi:10.1182/blood-2007-10-114900

[58] "NCCN Guidelines Version 2," Chorinc Myelogenous Leukemia, 2011.

[59] A. Hochhaus, M. Baccarani, M. Deininger, J. F. Apperley, J. H. Lipton, S. L. Goldberg, S. Corm, N. P. Shah, F. Cervantes, R. T. Silver, D. Niederwieser, R. M. Stone, H. Dombret, R. A. Larson, L. Roy, T. Hughes, M. C. Müller, R. Ezzeddine, A. M. Countouriotis and H. M. Kantarjian, "Dasatinib Induces Durable Cytogenetic Responses in Patients with Chronic Myelogenous Leukemia in Chronic Phase with Resistance or Intolerance to Imatinib," Leukemia, Vol. 22, No. 6, 2008, pp. 1200-1206.

[60] E. Jabbour, A. Fullmer, J. Cortes and H. Kantarjian, "Clinical Algorithms for the Treatment of Patients with Chronic Myeloid Leukemia: The 2010 PerspectiveClinical Lymphoma, Myeloma and Leukemia-2010: 10: Suppl 1:S6-S13.B. M. S. Giambastiani, 'Evoluzione 
Idrologica ed Idrogeologica Della Pineta di San Vitale (Ravenna),," Ph.D. Thesis, Bologna University, Bologna, 2007.

[61] G. Rosti, F. Palandri, F. Castagnetti, M. Breccia, L. Levato, G. Gugliotta, A. Capucci, M. Cedrone, C. Fava, T. Intermesoli, G. R. Cambrin, F. Stagno, M. Tiribelli, M. Amabile, S. Luatti, A. Poerio, S. Soverini, N. Testoni, G. Martinelli, G. Alimena, F. Pane, G. Saglio and M. Baccarani, "GIMEMA CML Working Party. Nilotinib for the Frontline Treatment of $\mathrm{Ph}(+)$ Chronic Myeloid Leukemia," Blood, Vol. 114, No. 24, 2009, pp. 4933-4938. doi:10.1182/blood-2009-07-232595

[62] J. E. Cortes, D. Jones, S. O’Brien, E. Jabbour, M. Konopleva, A. Ferrajoli, T. Kadia, G. Borthakur, D. Stigliano, J. Shan and H. Kantarjian, "Nilotinib as Front-Line Treatment for Patients with Chronic Myeloid Leukemia in Early Chronic Phase," Journal of Clinical Oncology, Vol. 28, No. 3, 2010, pp. 392-397. doi:10.1200/JCO.2009.25.4896

[63] G. Saglio, D. W. Kim, S. Issaragrisil, I. P. Coutre, G. Etienne, C. Lobo, R. Pasquini, R. E. Clark, A. Hochhaus, T. P. Hughes, N. Gallagher, A. Hoenekopp, M. Dong, A. Haque, R. A. Larson and H. M. Kantarjian, "ENESTnd Investigators. Nilotinib versus imatinib for newly diagnosed chronic myeloid leukemia," The New England Journal of Medicine, Vol. 362, No. 24, 2010, pp. 22512259. doi:10.1056/NEJMoa0912614

[64] H. Kantarjian, N. P. Shah, A. Hochhaus, J. Cortes, S. Shah, M. Ayala, B. Moiraghi, Z. Shen, J. Mayer, R. Pasquini, H. Nakamae, F. Huguet, C. Boqué, C. Chuah, E. Bleickardt, M. B. Bradley-Garelik, C. Zhu, T. Szatrowski, D. Shapiro and M. Baccarani, "Dasatinib versus Imatinib in Newly Diagnosed Chronic-Phase Chronic Myeloid Leukemia," The New England Journal of Medicine, Vol. 362 , No. 24, 2010, pp. 2260-2270. doi:10.1056/NEJMoa1002315

[65] A. Hochhaus, H. M. Kantarjian, M. Baccarani, J. H. Lipton, J. F. Apperley, B. J. Druker, T. Facon, S. L. Goldberg, F. Cervantes, D. Niederwieser, R. T. Silver, R. M. Stone, T. P. Hughes, M. C. Muller, R. Ezzeddine, A. M. Countouriotis and N. P. Shah, "Dasatinib Induces Notable Hematologic and Cytogenetic Responses in ChronicPhase Chronic Myeloid Leukemia after Failure of Imatinib Therapy," Blood, Vol. 109, No. 6, 2007, pp. 23032309. doi:10.1182/blood-2006-09-047266

[66] N. P. Shah, H. M. Kantarjian, D. W. Kimatinib, D. Réa, P. E. Dorlhiac-Llacer, J. H. Milone, J. Vela-Ojeda, R. T. Silver, H. J. Khoury, A. Charbonnier, N. Khoroshko, R. L. Paquette, M. Deininger, R. H. Collins, I. Otero, T. Hughes, E. Bleickardt, L. Strauss, S. Francis and A. Hochhaus, "Intermittent Target Inhibition with Dasatinib $100 \mathrm{mg}$ Once Daily Reserves Efficacy and Imatinib Proves Tolerability in Imatinib-Resistant and -Intolerant Chronic-Phase Chronic Myeloid Leukemia," Journal of Clinical Oncology, Vol. 26, No. 19, 2008, pp. 3204-3212. doi:10.1200/JCO.2007.14.9260

[67] H. M. Kantarjian, F. Giles, N. Gattermann, K. Bhalla, G. Alimena, F. Palandri, G. J. Ossenkoppele, F. E. Nicolini, S. G. O'Brien, M. Litzow, R. Bhatia, F. Cervantes, A. Haque, Y. Shou, D. J. Resta, A. Weitzman, A. Hochhaus,
P. le Coutre, "Nilotinib (Formerly AMN107), a Highly Selective BCR/ABL1 Tyrosine Kinase Inhibitor, Is Effective in Patients with Philadelfia Chromosome-Positive Imatinib Chronic Myelogenous Leukemia in Chronic Phase Following Imatinib Resistance and Intolerance," Blood, Vol. 110, No. 10, 2007, pp. 3540-3546. doi:10.1182/blood-2007-03-080689

[68] H. Kantarjian, F. Giles, L. Wunderle, K. Bhalla, S. O’Brien, B. Wassmann, C. Tanaka, P. Manley, P. Rae, W. Mietlowski, K. Bochinski, A. Hochhaus, J. D. Griffin, D. Hoelzer, M. Albitar, M. Dugan, J. Cortes, L. Alland and O. G. Ottmann, "Nilotinib in Imatinib-Resistant CML and Philadelfia Chromosome-Positive ALL," The New England Journal of Medicine, Vol. 354, No. 24, 2006, pp. 2542-2551. doi:10.1056/NEJMoa055104

[69] P. Le Coutre, O. G. Ottmann, F. Giles, D. W. Kim, J. Cortes, N. Gattermann, J. F. Apperley, R. A. Larson, E. Abruzzese, S. G. O’Brien, K. Kuliczkowski, A. Hochhaus, F. X. Mahon, G. Saglio, M. Gobbi, Y. L. Kwong, M. Baccarani, T. Hughes, G. Martinelli, J. P. Radich, M. Zheng, Y. Shou and H. Kantarjian, "Nilotinib (Formerly AMN107), a Highly Selective BCR/ABL1 Tyrosine Kinase Inhibitor, Is Active in Patients with Imatinib-Resistant or -Intolerant Accelerated-Phase Chronic Myemlogenous Leukemia," Blood, Vol. 111, No. 4, 2008, pp. 1834-1839. doi:10.1182/blood-2007-04-083196

[70] M. Ayala, R. Hurtado, K. Nacho, N. Tapia, M. Alvarado and A. Aguayo, "Compassionate Use of Nilotinib (AMN107) in Mexican Patients with Chronic Myeloid Leukemia (CML) Resistant or Intolerant to Imatinib," Blood, Vol. 110, No. 11, 2007.

[71] M. Ayala, R. Hurtado, N. Delgado, P. Vargas, L. Meillon, N. Tapia, M. Alvarado, J. De Diego, P. Azaola, M. Gonzalez, Y. Lugo, R. Hernandez, J. J. Kassack, S. Cleto, M. Nambo, G. Reyes, O. Cantu, A. Aguayo, I. Mucius, A. Herrera and K. Nacho, "Analysis of BCR/ABL1 Mutations in Mexican Patients with Imatinib-Resistant or -Intolerant Philadelfia-chromosome Positive Chronic Myeloid Leukemia ( $\mathrm{Ph}$ Positive CML) Treated with Nilotinib," Haematologica, Vol. 93, No. S1, 2008, p. 220.

[72] P. Laneuville, C. Dilea, O. Q. Yin, R. C. Woodman, J. Mestan and P. W. Manley, "Comparative in Vitro Cellular Data Alone Are Insufficient to Predict Clinical Responses and Guide the Choice of BCR/ABL1 Inhibitor for Treating Imatinib-Resistant Chronic Myeloid Leukemia," Journal Clinical Oncology, Vol. 28, No. 11, 2010, Article No. e169-e171. doi:10.1200/JCO.2009.26.4945

[73] E. Jabbour, G. Saglio, T. Hughes and H. Kantarjian, "Suboptimal Responses in Chronic Myeloid Leukemia. Implications and Management Strategies," Cancer, Vol. 118, No. 5, 2011, pp. 1181-1191. doi:10.1002/cncr.26391

[74] D. L. White and T. P. Hughes, "Predicting the Response of CML Patients to Tyrosine Kinase Inhibitor Therapy," Current Hematologic Malignancy Reports, Vol. 4, No. 2, 2009, pp. 59-65. doi:10.1007/s11899-009-0009-2

[75] J. Radich, "Stem Cell Transplant for Chronic Myeloid Leukemia in the Imatinib Era," Seminars in Hematology, Vol. 47, No. 4, 2010, pp. 354-361. doi:10.1053/j.seminhematol.2010.06.008 
[76] S. Saussele, M. Lauseker, A. Gratwohl, D. W. Beelen, D. Bunjes, R. Schwerdtfeger, H. J. Kolb, A. D. Ho, C. Falge, E. Holler, G. Schlimok, A. R. Zander, R. Arnold, L. Kanz, R. Dengler, C. Haferlach, B. Schlegelberger, M. Pfirrmann, M. C. Müller, S. Schnittger, A. Leitner, N. Pletsch, A. Hochhaus, J. Hasford and R. Hehlmann, "German CML Study Group. Allogenic Hematopoietic Stem Cell Transplantation (Allo SCT) for Chronic Myeloid Leukemia in the Imatinib Era: Evaluation of Its Impact within a Subgroup of the Randomized German CML Study IV," Blood, Vol. 115, No. 10, 2010, pp. 1880-1885. doi:10.1182/blood-2009-08-237115

[77] J. Pavlu, R. M. Szydlo, J. M. Goldman and J. F. Apperley, "Three Decades of Transplantation for Chronic Myeloid Leukemia: What have We Learned?" Blood, Vol. 117, No. 3, 2011, pp. 755-763. doi:10.1182/blood-2010-08-301341

[78] D. Kilojkovic, E. Nicholson, J. F. Apperley, T. Holyake, P. Shepherd, M. Drummond, R. Szydlo, M. Bua, L. Foroni, A. Reid, J. S. Khorashad, H. de Lavallade, K. Rezvani, C. Paliompeis, J. M. Goldman and D. Marin, "Early Prediction of Success or Failure of Treatment with Second-Generation Tyrosine Kinase Inhibitors in Patients with Chronic Myeloid Leukemia," Haematologica, Vol. 95, No. 2, 2010, pp. 224-231. doi:10.3324/haematol.2009.012781

[79] "NCCN Clinical Practice Guidelines in Oncology," National Comprehensive Cancer Network, 2012.

[80] P. J. Tutxchka, E. A. Copelan and J. P. Klein, "Bone Marrow Transplantation for Leukemia Following a New Busulfan and Cyclophsohamide Regimen," Blood, Vol. 70, No. 5, 1987, pp. 1382-1388.

[81] F. Dazzi, R. M. Szydlo, C. Craddock, N. C. P. Cross, J. Kaeda, A. Chase, E. Olavarria, F. van Rhee, E. Kanfer, J. F. Apperley and J. M. Goldman, "Comparison of Single-Dose and Escalating-Dose Regimens of Donor Lymphocyte Infusion for Relapse after Allografting for Chronic Myeloid Leukemia," Blood, Vol. 95, No. 1, 2000, pp. 67-71.

[82] E. Klyuchnikov, N. Kroger, H. Brummendorf, A. Wiedemann and A. U. Bacher, "Current Status and Perspectives of Tyrosine Kinase Inhibitor Treatment in the Posttransplant Period in Patients with Chronic Myelogenous Leukemia (CML)," Biology Blood Marrow Transplantation, Vol. 16, No. 3, 2010, pp. 301-310. doi:10.1016/j.bbmt.2009.08.019

[83] M. Talpaz, R. T. Siver, B. J. Druker, J. M. Goldman, C. Gambacorti-Passerini, F. Guilhot, C. A. Schiffer, T. Fischer, M. W. Deininger, A. L. Lennard, A. Hochhaus, O. G. Ottmann, A. Gratwohl, M. Baccarani, R. Stone, S. Tura, F. X. Mahon, S. Fernandes-Reese, I. Gathmann, R. Capdeville, H. M. Kantarjian and C. L. Sawyers, "Imatinib Induces Durable Hematologic and Cytogenetic Responses in Patients with Accelerated Phase Chronic
Myeloid Leukemia: Results of Phase II Study," Blood, Vol. 99, No. 6, 2002, pp. 1928-1937. doi:10.1182/blood.V99.6.1928

[84] H. Kantarjian, J. E. Cortes, D. W. Kim, P. DorlhiacLlacer, R. Pasquini, J. DiPersio, et al., "Phase III Study of Dasatinib $140 \mathrm{mg}$ Once Daily versus $70 \mathrm{mg}$ Twice Daily in Patients with Chronic Myeloid Leukemia in Accelerated Phase Resistant or Intolerant to Imatinib: 15-Month Median Follow-Up," Blood, Vol. 113, No. 25, 2009, pp. 6322-6329. doi:10.1182/blood-2008-11-186817

[85] M. Baccarani, J. Cortes, F. Pane, D. Niederwieser, G. Saglio, J. Apperley, F. Cervantes, M. Deininger, A. Gratwohl, F. Guilhot, A. Hochhaus, M. Horowitz, T. Hughes, H. Kantarjian, R. Larson, J. Radich, B. Simonsson, R. T. Silver, J. Goldman and R. Hehlmann, "Chronic Myeloid Leukemia: An Update of Concepts and Management Recommendations of European LeukemiaNet," Journal of Clinical Oncology, Vol. 27, No. 35, 2009, pp. 6041-6051. doi:10.1200/JCO.2009.25.0779

[86] B. J. Druker, C. L. Sawyers, H. Kantarjian, D. J. Resta, S. F. Reese, J. M. Ford, R. Capdeville and M. Talpaz, "Activity of a Specific Inhibitor of the BCR/ABL1 Tyrosine Kinase in the Blast Crisis of Chronic Myeloid Leukemia and Acute Lymphoblastic Leukemia with the Philadelphia Chromosome," The New England Journal Medicine, Vol. 344, No. 14, 2001, pp. 1038-1042. doi:10.1056/NEJM200104053441402

[87] J. Cortes, P. Rousselot, D. W. Kim, E. Ritchie, N. Hamerschlak, S. Coutre, A. Hochhaus, F. Guilhot, G. Saglio, J. Apperley, O. Ottmann, N. Shah, P. Erben, S. Branford, P. Agarwal, A. Gollerkeri and M. Baccarani, "Dasatinib Induces Complete Hematologic and Cytogenetic Responses in Patients with Imatinib-Resistant or -Intolerant Chronic Myeloid Leukemia in Blast Crisis," Blood, Vol. 109, No. 8, 2007, pp. 3207-3213. doi:10.1182/blood-2006-09-046888

[88] O. Ottmann, R. Larson, H. Kantarjian, P. Le Coutre, M. Baccarani, A. Weitzman and F. Giles, "Nilotinib MonoTherapy in Patients with Imatinib-Resistant or Intolerant $\mathrm{Ph}$ Positive CML in Blast Crisis or Relapsed/Refractory $\mathrm{Ph}$ Positive Acute Lymphoblastic Leukemia," Haematologica, Vol. 92, Suppl. 1, 2007, p. 207.

[89] M. Baccarani, G. Saglio, J. Goldman, A. Hochhaus, B. Simonsson, F. Appelbaum, J. Apperley, F. Cervantes, J. Cortes, M. Deininger, A. Gratwohl, F. Guilhot, M. Horowitz, T. Hughes, H. Kantarjian, R. Larson, D. Niederwieser, R. Silver and R. Hehlmann, "European LeukemiaNet. Evolving Concepts in the Management of Chronic Myeloid Leukemia: Recommendations from an Expert Panel on Behalf of the European Leukemia Net," Blood, Vol. 108, No. 6, 2006, pp. 1809-1820. doi:10.1182/blood-2006-02-005686 